\title{
Humanização da Assistência de Enfermagem Baseada na Termorregulação do Recém-Nascido Pré-Termo Internado no Centro de Terapia Intensiva Neonatal
}

\author{
Mendonça, Aline Maria Carvalho Maia; Leite, Álvaro Jorge Madeiro; Rolim, Karla \\ Maria Carneiro; Ferreira, José Hernevides Pontes; Nascimento, Velma Dias do; \\ Pinto, Kátia Costa Savioli Harrismana de Andrade \\ Universidade Federal do Ceará (Ufc) — alinecarvalhomaia@hotmail.com
}

INTRODUÇÃO: a termorregulação neonatal torna-se uma função fisiológica intimamente relacionada com a transição e sobrevivência de recém-nascidos pré-termo (RNPT), que em condições extremas de temperatura, são incapazes de manter a homeostase. o cuidar de enfermeiros e técnicos/auxiliares de enfermagem em Unidades de Terapia Intensiva Neonatal (UTINs) deve ser permeado de humanismo e satisfação, pois a humanização envolve muito mais do que conhecimentos e habilidades técnicas. Humanizar não é técnica ou artifício, mas, sim, um processo vivencial a permear toda atividade dos profissionais no intuito de realizar e oferecer o melhor tratamento ao ser humano, dentro das circunstâncias peculiares vividas em cada momento do hospital. por isso, nos questionamos: será que o cuidado baseado na termorregulação do RNPT pelo profissional atuante na UTIN é permeado de humanização?. OBJETIVO: Identificar a humanização na assistência de Enfermagem baseada na termorregulação do RNPT internado no Centro de Terapia Intensiva Neonatal. METODOLOGIA: Estudo quantitativo-descritivo. Realizado no Centro de Terapia Intensiva Neonatal (CTINE) do Hospital Infantil Albert Sabin (HIAS), na cidade de Fortaleza (CE), pertencente à Secretaria Estadual da Saúde do Ceará (SESA). Tendo com sujeito toda a equipe de Enfermagem deste setor, como Enfermeiros (E) e Técnicos/Auxiliares de Enfermagem (TAE), passando a ser excluídos apenas aqueles profissionais que permaneciam de férias/licença saúde, bem como os que não aceitaram participar da pesquisa. Dados coletados entre maio-julho de 2012, por um instrumento elaborado para analisar e observar os cuidados prestados por essa equipe e organizados em tabela por meio do programa Excel, da Microsoft Office 2007. Aprovado pelo Comitê de Ética da instituição sob o protocolo ํㅡ 23904, seguindo os princípios bioéticos previstos na Resolução 196/96 do Conselho Nacional de Saúde. RESULTADOS: Diversos foram os achados, mas alguns se destacam por sua importância fisiológica e humana. ao se depararem com o RNPT hipertérmico, 11 TAE realizavam a abertura da portinhola na intenção de conter a febre, enquanto somente 6 e faziam o mesmo. na hipotermia, e elevaram a temperatura do ar na incubadora aquecida e TAE a de pele. dos procedimentos diversos, 7 e e 18 TAE escolhem a portinhola, ao invés da lateral totalmente aberta. ao alarmar a incubadora, os TAE a desligaram e $\mathrm{E}$ ajustaram os parâmetros e verificaram a temperatura do bebê. ao manuseio cuidadoso, comprovouse $100 \%$, sendo preconizado pela própria unidade estudada. CONCLUSÃO: Foi possível caracterizar os cuidados oferecidos por toda a equipe de Enfermagem ao RNPT, observando que falhas ainda existem sendo necessário formular protocolos para verificar essa temperatura, fundamentando um cuidado humanizado. Destacamos a importância de um olhar holístico por parte da equipe de Enfermagem, sendo necessário estabelecer rotinas acerca da termorregulação.

Mendonça, Aline Maria Carvalho Maia; Leite, Álvaro Jorge Madeiro; Rolim, Karla Maria Carneiro; Ferreira, José Hernevides Pontes; Nascimento, Velma Dias do; Pinto, Kátia Costa Savioli Harrismana de Andrade. Humanização da Assistência de Enfermagem Baseada na Termorregulação do Recém-Nascido Pré-Termo Internado no Centro de Terapia Intensiva Neonatal. In: Anais do Congresso Internacional de Humanidades \& Humanização em Saúde [= Blucher Medical Proceedings, num.2, vol.1]. São Paulo: Editora Blucher, 2014. ISSN 2357-7282

DOI 10.5151/medpro-cihhs-10413 